\title{
$\underline{\mathbf{P}-104}$
}

\section{Synthesis of Capsaisin Derivatives and its Antibacterial Activity}

Iswatun Hasanah $^{1,2}$, Habsah Mohamad ${ }^{1,2, *}$, Asnuzilawati Asari ${ }^{1,2}$, Jasnizat Saidin ${ }^{1}$ and Mohd Effendy Abd Wahid ${ }^{1}$

${ }^{1}$ Institute of Marine Biotechnology, ${ }^{2}$ Department of Chemical Sciences, Faculty of Science and Technology, Universiti Malaysia Terengganu,21030 K. Terengganu,Terengganu, Malaysia; E-mail: habsah@umt.edu.my

Seven capsaicin analogues were synthesized by condensation of vanillylamine and acyl chlorides in a biphase $\mathrm{H}_{2} \mathrm{O} / \mathrm{CHCl}_{3}$ system. The structures of these compounds were elucidated based on spectroscopic methods including NMR and IR, CHNS analysis and comparison with literature data. The antibacterial activity of the compounds were also reported.

Keywords: Capsaicin, antibacterial, fatty acid chloride, vanillylamine. 